\title{
Clinical Supervision of Midwifery Students at the University Teaching Hospital School of Nursing and Midwifery in Lusaka, Zambia
}

\author{
Naomi Bweupe $^{1 *}$, Catherine M. Ngoma ${ }^{2}$, Brenda Sianchapa ${ }^{2}$ \\ ${ }^{1}$ Lusaka Schools of Nursing, Midwifery and Theatre Nursing, Lusaka, Zambia \\ ${ }^{2}$ University of Zambia, School of Nursing Sciences, Lusaka, Zambia \\ Email: *nebweupe@yahoo.co.uk
}

How to cite this paper: Bweupe, N., Ngoma, C.M. and Sianchapa, B. (2018) Clinical Supervision of Midwifery Students at the University Teaching Hospital School of Nursing and Midwifery in Lusaka, Zambia. Open Journal of Nursing, 8, 372-389. https://doi.org/10.4236/ojn.2018.86030

Received: November 9, 2017

Accepted: June 19, 2018

Published: June 22, 2018

Copyright $\odot 2018$ by authors and Scientific Research Publishing Inc. This work is licensed under the Creative Commons Attribution-NonCommercial International License (CC BY-NC 4.0). http://creativecommons.org/licenses/by-nc/4.0/

\begin{abstract}
Introduction: Clinical supervision plays a significant role in the acquisition of psychomotor skills by student midwives during training leading to the provision of high quality midwifery care. However, the acquisition of the psychomotor skills required for successful practice and learning can only be acquired if student midwives are supported and guided by clinical supervisors in their learning environments. Main Objective: The main objective of the study was to determine factors influencing clinical supervision of Student Midwives in Lusaka Urban District. Methodology: A cross-sectional study design that employed both quantitative and qualitative methods was used. The study population comprised 124 Nurses and Midwives working in Lusaka urban District. Self-administered questionnaires were used to collect data from the Nurses and midwives and a focus group discussion guide was used to guide discussions with the student midwives at Lusaka College of Nursing and Midwifery and a total of three focus group discussions were conducted. Quantitative data were entered into by Statistical Package Social Sciences (SPSS) version 22 for windows. Chi-square test was used to test associations among variables. The confidence interval was set at $95 \%$ with a significance level of 0.05 . Qualitative data were analysed using content analysis to classify words into themes and categories by looking for repeated ideas or patterns of thoughts. Results: The findings showed that a high percentage of the clinical supervisors $(89.5 \%)$ had not been trained in clinical supervision and most respondents had moderate knowledge on clinical supervision of students. Majority of the respondents (63\%) exhibited inadequate supervision skills. The attitudes of all the supervisors towards supervision were positive. A large percentage of respondents (73\%) were competent in clinical supervision. However the learning environment considered to be poor by most respon-
\end{abstract}


dents $(61 \%)$. The study revealed a significant association between clinical supervision and the respondents' knowledge on clinical supervision ( $p$-value of $0.00)$. Conclusion: The current study showed that clinical supervision was untrained and had inadequate supervision skills and the learning environment was poor. There is need therefore to train clinical supervisors and improve the students' learning environment in order to enhance teaching and learning. The study offers a valuable insight into the factors influencing students' midwives learning in clinical learning environment.

\section{Keywords}

Clinical Supervision, Student Midwives, Knowledge, Attitude, Competence/Skills and Learning Environment

\section{Introduction}

Clinical supervision is a formal process of professional support and learning that enables individual practitioners to develop knowledge and competence, assumes responsibility for their own practice, and enhances patient protection and safety of care in a wide range of situations [1]. This involves the indirect and direct observation of a clinical supervisor who is an "appropriately qualified and recognised professional who guides students' education and training during clinical placements" [2]. Clinical supervision is a statutory requirement for midwives; before a student midwife graduates from training and register to practice, he/she must demonstrate competency in midwifery [3].

A student midwife must be able to put into practice what she has learned in theory, to apply the knowledge obtained in the classroom to exercise educated judgement and make skilled observations throughout the giving of patient care [4]. This correlation of theory and practice and the building of meaningful experience must take place in the field of clinical practice under supervision by qualified personnel [5].

In Zambia, training of midwives is regulated by the General Nursing Council of Zambia (GNC); a regulatory body formed under 1970 Nurses and Midwives Act [6]. GNC as a regulatory body collaborates with International Council of Midwives (ICM). The General Nursing Council recognizes clinical supervision has an important part of clinical governance and a means of maintaining and improving standards of patient care [6]. Clinical supervision is a statutory requirement for midwives.

During midwifery training students are taught theory and practice. The theoretical aspects include scope of practice, legal aspects of midwifery, low and high risk pregnancies, labour, puerperium and the neonate [6]. The practical aspect include 20 normal deliveries, 10 abnormal deliveries, 10 Information, Education and Communication (IEC), 10 domiciliary visits, 10 long palpations, 40 short palpations, 10 special family planning cases, 10 ordinary family planning cases 
and 1 case study. Acquisition of these competencies requires supervision by a Tutor, Clinical Instructor and/or professional midwives with relevant qualification [7]. A clinical supervisor facilitates opportunities during a student's clinical practice events that enable the student to achieve learning objectives that is, to meet the competences required by the regulatory authority. Thus the clinical supervisor facilitates the integration of theory into practice and adequate transfer of the newly acquired clinical skills though this may be influenced by some factors.

Studies have revealed a number of factors influencing clinical supervision of student midwives such as supervisory relationship [8]. A study by in CHAM nursing college in Malawi on factors affecting acquisition of psychomotor clinical skills by students nurses and midwives found that student motivation, lack of resources, learning environment, knowledge gap between the qualified nurses and Tutors and role modeling [9]. Quality of time and access to one to one supervision influence students' clinical supervision. Other factors include availability of expertise, educational preparation and positive attitude of supervisor [10]. The main objective of the study is therefore to determine factors influencing clinical supervision of student Midwives in order to ensure the integration of theory to practice and adequate transference of newly acquired skills.

Clinical supervision of student midwives is a critical factor for skills acquisition, patient care and safety [11]. However, supervision of students at Lusaka School of midwifery is not adequately achieved due to a shortage of the teaching staff and midwives in the clinical areas. Lusaka school of midwifery currently has two Clinical Instructors and six Tutors and on average there are 5 to 8 Midwives on duty per shift in labour ward and these are expected to work with and supervise student Midwives including student Nurses on duty. The staffing levels per shift in both labour ward and NICU according to the records is 5 - 8 Nurses or midwives to work with a group of more than 40 students.

The ever increasing student population makes it difficult for the Midwives to monitor students and patients effectively. Furthermore, most of the clinical staff are not trained in student clinical supervision. The recommended staff/student supervision ratio is 1:6 and that of clinical instructor/students is 1:10 for them to work effectively but currently this is not the case. There also has been a public outcry on the caliber of the newly qualified midwives graduating from midwifery schools. It is against this background that this research study will be conducted with the purpose of exploring factors influencing clinical supervision of student midwives at Lusaka school of Midwifery.

Having a good number of trained Clinical Preceptors and Registered Midwives in a clinical site promote good and effective training of students. Shortage of staff in most of the clinical sites and increased population of students has contributed to limited supervision as per guidelines. There is limited published data on the topic in the country. The study aims to determine if available structure, skills of staff and attitudes contribute to effective supervision. It is hoped 
that the study findings will open a way for other scholars and researchers to look at this problem and further influence policy direction towards helping the Student Nurse Midwives acquire competencies to enable them practice as expert reflective practitioners and thus improving the quality of the midwifery profession.

\section{Research Objective}

The main aim of the study was to determine factors influencing clinical supervision of Student Midwives in Lusaka Urban District. The specific objectives were to assess level of knowledge of supervisor on clinical supervision of student midwives, determine attitudes of supervisors towards student midwives, identify competences of the supervisor of student midwives and assess the student midwives learning environment.

\section{Methodology}

A cross-sectional study to determine factors influencing Clinical Supervision of Student Midwives in Lusaka urban was used as little was known about the topic. The researcher employed both quantitative and qualitative methods to collect data. The quantitative method helped quantify the factors influencing clinical supervision of student midwives in Lusaka urban by use of self-administered questionnaires to study participants. The qualitative approach was used to uncover trends in thought and opinions, and dive deeper into the problem of clinical supervision. Qualitative data collection methods vary but this study used focus group discussions. The quantitative data collection tool was also exploratory in order to gain an insight into factors that influence clinical supervision of Student Midwives in Lusaka urban.

The study setting was in Lusaka at the University Teaching Hospital, a tertiary hospital with a bed capacity of 1500; and the five health facilities in Lusaka (Chipata, Chawama, Chilenje, and Matero first level district Hospitals and Kalingalinga Health Center); where the Student Nurse Midwives practice from as this was the natural location for study participants. The Obstetrics, Gynaecology wards and NICU will be used at UTH while the MCH and Labour wards in the five urban facilities were used.

The study population included the Nursing and Midwifery Staff who work in the facilities where student Midwives practice from in Lusaka Urban. These are the ones who are likely to be involved in clinical supervision of Student Midwives as they work with them. The Target Population were Nurses and Midwives in Lusaka in Urban who were working from the Obstetric wards and NICU at the UTH and the MCH; Labour wards in the urban clinics and the Midwives working at the Lusaka Schools of Nursing and Midwifery.

The purposive sampling method was used to select the study sample since the study population was limited. All the facilities and Registered Midwives where Student Midwives are practicing from in Lusaka were part of the study to enable 
the Research collect data from a representative sample. Nurses and Midwives with at least 1 year working experience who were working in clinical sites where Student Midwives do their Midwifery practice and were willing to give informed consent were recruited to participate in the study. These were resident employees of the study areas as part time Staff may not have been regularly in contact with Students. The sample size was calculated using the proportion of Nursing and Midwifery staff who work with Student Nurse Midwives as follows:

$$
n=Z^{2} P(1-P) \div d^{2}
$$

$P=$ proportion of the staff who work with students $=0.5$

$=50 \%$

$$
1-P=0.5
$$

$Z=1.96=$ Standard normal variant at $95 \%$ confidence level

$$
\begin{gathered}
d= \pm 5 \%= \pm 0.05 \\
n=1.96^{2} \times 0.5 \times 0.5 \div 0.05^{2}=384
\end{gathered}
$$

Adjusting for the population size of all staff working with students $=182$

The final $n=n \div[1+(n \div n)]$

Were $\mathrm{N}=182$, population size

$n=384$ calculated

Final $\mathrm{n}=384 \div[1+(384 \div 182)]=384 \div 3.11=124$

Therefore 124 participants who were eligible to participate in the study Midwives or Nurses

Data were collected from the respondents using a questionnaire. A questionnaire and focus group guide were used to collect data because all the respondents were literate and able to write in English language, which is the formal language of communication in the country. Questionnaires were given to participants for them to read and answer the questions. The questionnaire had five (5) sections covering demographic data of the respondents, knowledge, attitude, competences and skills for clinical supervisors. The questionnaire had both closed and open ended questions to enable the Researcher collect specific data and this allowed for free expression of participants on issues where they wanted to add more information that could have been missed out in closed ended questions. Focus group discussion guide were used during the FGDs to help guide participants on the topic under discussion.

Validity was measured by ensuring that the same questions were asked to each respondent in the same sequence during the focus group discussions. To ensure validity, questions were constructed in a simple, clear and precise way in order giving respondents an opportunity to give clear and precise answers on factors influencing clinical supervision of Student midwives. The data collection tools were checked by the research supervisors and experts in nurse/midwifery education such as the Standards and Education Managers at the General Nursing Council and the Principal tutors of midwifery schools. The Questionnaires had same questions that were clearly constructed to avoid ambiguity. 
Reliability was ensured by standardizing the instrument by testing the research tools before the main study was conducted using a pilot study in an environment with similar characteristics. To ensure reliability, a variety of open ended questions were used in the questionnaire to allow for spontaneous responses that gave more valid answers. A pilot study was carried out to check whether the instruments were able to bring out consistent information about factors influencing clinical supervision of Student Midwives.

The questionnaires were distributed to the respondents at their working places. Permission to carry out the study was sought from the respondents' before administering the questionnaires and the purpose of the study was concisely explained to the respondents during the process of distribution. The completed questionnaires were collected by the researcher within 48 hours after distribution. Participants were thanked after receiving the completed questionnaires.

Prior to the main study, a pilot study was conducted at Kabwe General Hospital and School of Nursing and Midwifery located in Kabwe town which is 135 kilometers from Lusaka City. The purpose of piloting the instrument was to obtain clarity, find out its appropriateness and obtain direction to the main study.

Ethical clearance to conduct the study was obtained from the University of Zambia Biomedical Research Ethics Committee (UNZABREC) and National Research Authority at $\mathrm{MOH}$ before collecting data. Permission was obtained from the Senior Medical Superintendents of the UTH and Kabwe General Hospital, General Nursing Council and District Health Office (DHO). Participants, participated in the study voluntarily and were informed of the right to withdraw at any time without negative implication. Written consent was obtained from all participants before they participated. Consideration was made to those who were not in a state of participating due to time and fatigue related to their work. The information that was collected was kept confidential (under lock and key). No names were indicated, however, the questionnaires and FGD guides had serial numbers for the purpose of data entry.

Data were collected using questionnaires and focus group discussion guides. Questionnaires were used on 124 respondents and there was $100 \%$ response rate, and the Focus Group Discussion Guide was used on three (3) groups of five (5) student midwives each with the response rate of fourteen (14) $93.3 \%$ as one (1) $6.7 \%$ participant could not participate due to academic commitment on the day and time of data collection. The data was collected from UTH Women's and Newborn Hospital, Lusaka College of Nursing and Midwifery, four (4) first levels hospitals and one (1) health center in Lusaka City. A Pilot study was done at Kabwe General Hospital and Kabwe School of Nursing and Midwifery in Kabwe District, after which the main study was undertaken.

After data collection, the questionnaires that were used were counted and checked for completeness, legibility, accuracy and consistency. Answers from closed ended questions were coded and entered on the computer using SPSS version 22. Answers from open ended questions were read through, and answers that belonged together were grouped, a process known as categorization [12]. 
Numerical codes (1, 2, 3 and so on) were then assigned to each group and the data were entered on the computer using SPSS version 22. Chi-square and linear regression was used to test for associations between dependent and independent variables. The cut off point for statistical significance was set at $5 \%$, and p-values of 0.05 or less was considered statistically significant. The confidence interval was set at $95 \%$.

After each focus group discussion, the recorded information from the voice recorder was played to the participants to check for consistency of the information recorded and study participants were asked to clarify any points which were not clear. Transcription of the data was done which involved writing a full report of the focus group discussions, using participants' own words and expressions.

Data were read through to get the key points and general ideas expressed. Content analysis, which involved classifying words in a text into a few categories chosen because of their theoretical importance [13] was used to analyse data. Answers from the three (3) groups of students were compared.

\section{Results}

The findings revealed that $35.5 \%$ of the respondents were aged between 35 and 44 years (Table 1 ) and were female (98.4\%). In terms of academic qualifications, most respondents (65.3\%) had Certificates in Midwifery and 35.5\% of the respondents reported having supervised for 1 to 3 years. Though most of the respondents had medium knowledge level on clinical supervision, a high percentage of them $(89.5 \%)$ had not been trained in clinical supervision.

The findings of the study showed that majority (63\%) of the respondents exhibited inadequate supervision skills (Figure 1). However, most of the respondents had positive attitudes towards clinical supervision. The study showed an association between clinical supervision and knowledge of supervision ( $p$-value $=0.000)$, see Table 2 . Most respondents (73\%) exhibited competence in midwifery procedures. Concerning learning environment, most respondents (61\%) described the learning environment as being poor.

\section{Clinical Supervision skills}

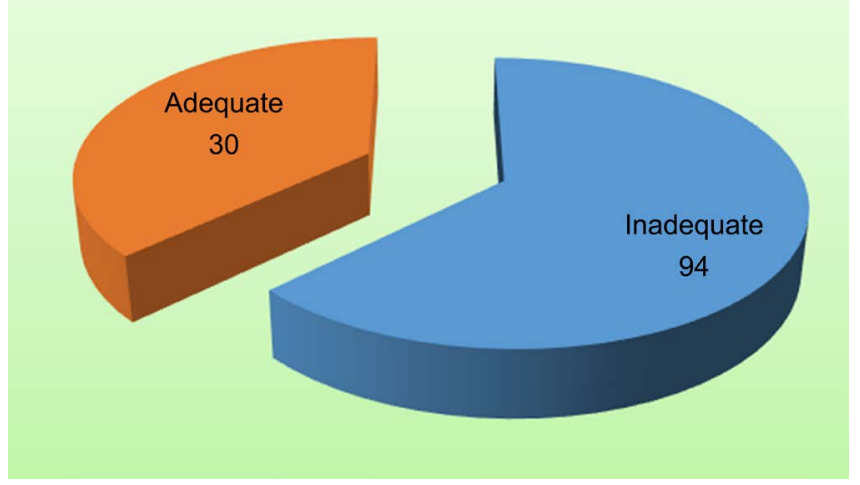

Figure 1. Clinical supervision skill. 
Table 1. Demographic Characteristics $(\mathrm{n}=124)$.

\begin{tabular}{|c|c|c|}
\hline Demographic Characteristics & Frequency & Percent \\
\hline \multicolumn{3}{|l|}{ Age } \\
\hline $21-34$ & 42 & 33.9 \\
\hline $35-44$ & 44 & 35.5 \\
\hline $45-55$ & 32 & 25.8 \\
\hline Above 55 & 6 & 4.8 \\
\hline Total & 124 & 100.0 \\
\hline \multicolumn{3}{|l|}{ Sex } \\
\hline Male & 2 & 1.6 \\
\hline Female & 122 & 98.4 \\
\hline Total & 124 & 100.0 \\
\hline \multicolumn{3}{|l|}{ Academic Qualifications } \\
\hline Certificate in Midwifery & 81 & 65.3 \\
\hline BSc Nursing & 23 & 18.5 \\
\hline Master's Degree & 3 & 2.4 \\
\hline Other & 17 & 13.7 \\
\hline Total & 124 & 100.0 \\
\hline \multicolumn{3}{|l|}{ Years Supervising Students } \\
\hline Less than 1 year & 16 & 12.9 \\
\hline $1-3$ years & 44 & 35.5 \\
\hline $4-6$ years & 28 & 22.6 \\
\hline Above 6 years & 36 & 29.0 \\
\hline Total & 124 & 100.0 \\
\hline \multicolumn{3}{|l|}{ Trained in Supervision } \\
\hline Valid Yes & 13 & 10.5 \\
\hline No & 111 & 89.5 \\
\hline Total & 124 & 100 \\
\hline
\end{tabular}

Table 2. Association between clinical supervision and knowledge of clinical supervision by the respondents $(n=124)$.

\begin{tabular}{ccccc}
\hline $\begin{array}{c}\text { Knowledge of clinical } \\
\text { supervision }\end{array}$ & \multicolumn{2}{c}{ Clinical supervision } & Total & $P$ value \\
\hline & Inadequate & Adequate & & \\
Low & $33(82.5 \%)$ & $7(17.7 \%)$ & $40(100 \%)$ & \\
Moderate & $41(68.3 \%)$ & $19(31.7 \%)$ & $60(100 \%)$ & 0.000 \\
High & $4(16.7 \%)$ & $20(83.3 \%)$ & $24(100 \%)$ & \\
Total & $78(62.9 \%)$ & $46(37.1 \%)$ & $124(100 \%)$ & \\
\hline
\end{tabular}

\section{Discussion of Findings}

The main objective of the study was to determine factors influencing clinical supervision of Student Midwives in Lusaka Urban District. The findings revealed 
that $35.5 \%$ of the respondents were aged between 35 and 44 years. They were more respondents aged between 35 and 44 years, perhaps indicating that younger midwives and nurses were not being employed due to the economic recession the country is experiencing or it could also be due to an increase in post basic qualifications being offered in the country like Advanced Diploma in Paediatric Nursing and Child Health, Critical Care Nursing, Clinical Instructor Program and Bachelor of Science in Nursing at universities.

The study findings on gender showed that the majority of the respondents were female, constituting $98.4 \%$ of the sample. There were more female midwives and Nurses because previously Nursing and Midwifery were regarded female careers and hence more females were trained as Nurses and midwives. In addition, culturally women are considered to be care givers and the ones expected to attend to pregnant women. These findings are similar to those reported by a study that indicated few student male midwives (28\%) compared to the females $(72 \%)$. On the academic qualifications of those involved in clinical supervision, most respondents (65.3\%) had a Certificate in Midwifery. There were more midwives with a certificate in midwifery supervising students because these are specialized professionals mainly employed in the midwifery section in the health sector. These findings are contrary to a study conducted in Tanzania which showed that non-qualified individuals were involved in provision of clinical supervision of student midwives [5] [14].

All the respondents who participated in this study were involved in clinical supervision of student midwives and most of them have been supervising student midwives for 1 to 3 years (35.5\%). This suggests that most of the clinical supervisors lacked experience in terms of supervision of students. On whether the Clinical Supervisors had been trained in clinical supervision of student midwives, the majority of the respondents (89.5\%) responded in the negative. This could be attributed to lack of clinical Instructor training in the country hence the need for the relevant authorities to look into matter; the school of Nursing in Lusaka trains Clinical Instructors but the enrollment numbers are low as institutions only think of those working in schools as instructors to be the ones eligible for training; Schools also have few staff working as instructors making it a challenge to release them to go for training. Trained staff in clinical field has the responsibility to teach although few have formal training in supervision. This entails that most of the staff working with student midwives required to undergo training in clinical supervision for them to effectively and efficiently work with student midwives. The knowledge they could be using may be basic to handle the task of supervision. The explanation for this could be that student supervisors are mainly thought of as those in training schools and these could have learnt clinical supervision as part of nursing education during training as Clinical instructors or Bachelor's Degree in Nursing.

Similarly results from a study in Malawi showed that nurses who had low education level felt that students did not need to be assisted as they felt inferior 
unlike the nurses who were highly educated as they were able to identify the needs of students [9] [15] [16] [17] [18].

In the same way, since the students are assisted by different cadres with different experiences and educational level in various hospitals, this could be true as regards to the knowledge gap which is there among these carders that eventually affects the transmission of skills to students. Effective clinical teachers need to be prepared and keep updated with current trends in nursing and midwifery. This was supported by respondents who observed that students expected their clinical teachers to be knowledgeable and skilled in the fields of nursing and midwifery.

\section{Knowledge of Clinical Supervision by Student Midwives Supervisors}

The current study revealed that $61.3 \%$ of the respondents spent more than 60 minutes per shift with students and they spent more than 60 minutes per shift with a group of students because clinical supervisors have so many students to supervise at any given time due to the ever increasing population of students. This finding was contrary to the feedback from students who participated in the focus group discussion. The students mentioned that they are usually found on the wards working to fulfill tasks assigned to them by the qualified staff who had little time to attend to them. The students thus do more of routine works and have little time to accomplish their objectives to help them comprehend what they are expected to learn.

Most respondents (66\%) used group sessions as a mode of supervision of students. Group sessions are the most popular method of supervision at Lusaka school of midwifery because of the large numbers of students being enrolled in the programs. Although one to one method supervision is the most effective method this may not be feasible due to shortage of clinical supervisors. The most common method of meeting clinical learning needs of students as reported by the respondents was demonstration of midwifery procedure before practice (32\%). Demonstration of procedures before practice was the most common method of meeting students' clinical needs because they believed when a student observed something they were likely to remember. This finding is in line with what some scholars on clinical education also state, although emphasis should be on using mixed methods. The mixed methods enable students acquire different skills according to their abilities. The statistics of the respondents trained to do clinical supervision as revealed in this study also suggest that lack of training limits the use of other teaching methods.

Concerning how they ensured the progress of students during clinical trials, half of the respondents (51.6\% ) said by meeting with clinical staff, $32.3 \%$ said by weekly reports, $24.2 \%$ said by monthly reports, and $16.1 \%$ said by "Other means". This finding could be attributed to the fact that most qualified nurses and midwives despite appreciating the need to supervise students still believe the 
responsibility should be shouldered by staff from schools.

The findings indicate that $27.8 \%$ of the respondents used continuous evaluation method, $24.1 \%$ used end of demonstration/simulation/role play, $18.8 \%$ used workbooks, $13.9 \%$ used final practical assessment, 5.2\% used written field reports from the ward supervisors and $2.2 \%$ used others methods. These findings reveal that most supervisors use meetings with clinical staff as a method of ensuring students' progress. The monthly and weekly reports are not usually used. Records that are documented as reports have a powerful and lasting benefits in monitoring students' progress as these may act as reference points to help students. If a student requires help the reports may be useful to notice areas of weaknesses since these as kept as records for the wards, school and students can also reflect on the reports to see areas they need to improve in. The fact that fewer respondents reported to be using reports also demonstrates the poor documentation among nurses and midwives. This is like not monitoring a child's growth and development; a vital aspect to assess individual's physical and mental development. The results may prove disastrous as important indicators to progress would have been missed early and delayed identification becomes very difficult and too costly if not impossible to treat.

When asked the respondents gave feedback to student midwives with regard to clinical training, $29.5 \%$ of the respondents said 'other times, $23.3 \%$ said when they requested, $19.3 \%$ said at the end of the course, $15.9 \%$ said at the end of the semester, and $11.9 \%$ said at the end of the year. The participants in the FGD also identified lack of motivation as the reason most supervisors delay in giving feedback. The factors identified to cause this were mainly staffing levels and attitude of supervisors. The fact that most supervisors are not trained in clinical supervision also contributes to them not giving feedback regularly even when problems have been noticed in trainees. Studies have also found that knowledge gap between nurses and tutors hindered clinical skill acquisition by students. Most students reported that they had noted a discrepancy when it came to performing of procedures among the tutors themselves as well as the clinical nurses. It is vital that nurses understand what is meant by clinical supervision and what it is they are being urged to take on. Nurses should also be aware that there may be different but equally valuable perspectives on supervision and not allow this to become yet another barrier to its implementation; Nurses are expected to take on greater responsibility an appropriate support network that encourages exploration of practice can only be of benefit [11] [15] [16]. The aspect of professional responsibility and accountability towards work including supervision of students need to be strengthened for school staff and clinical staff to frequently liaise to help impart knowledge to students.

The study showed that $46.5 \%$ of the respondents gave feedback individually to students in a private place, $18.1 \%$ gave feedback in a group of fellow students, and $16.3 \%$ gave feedback on the spot when attending to a client, $10.3 \%$ gave feedback in the presence of the ward sister and $6.3 \%$ gave feedback in a class- 
room with preceptors/clinical instructors. It is encouraged that students feedback take different forms depending on situations. At times there is need to council a student on weaknesses privately while problems affecting the entire group may call for group discussions. The participants in the FGD mentioned that they appreciated staff who talk to them privately soon after they have done some work so that they recall the areas to be worked on and avoid future mistakes "it feels good to know that someone cares for your professional growth and motivates us to do more" said most of the participants and others just acknowledged that.

The findings revealed that the most common strategy used by the respondents in the clinical area was demonstration (24\%), $12.8 \%$ of the respondents used nursing round and clinical meetings respectively, $11.1 \%$ used clinical judgment, $10.6 \%$ used problem solving, $8.5 \%$ used case study/presentation and 1.3 used other strategies. Demonstration is thought to be a very effective method of clinical teaching as students usually recall what they observe being done. This still need to be accompanied by other strategies that are relevant for the task being taught. Participants in the FDG also echoed the need for this method which they said was rarely done in clinical area as staff spent time doing their ward duties mainly. Lack of knowledge on supervision and methods to use may be a contributing factor. Some staff felt overwhelmed by work and had little time to spend with students. Training on supervision and continuing professional development may help supervisors use the different strategies to supervise students rather than depending on demonstration only which may be challenging when one has to attend to other tasks.

Most of the respondents (41.6\%) said that a conducive learning environment provides teaching and learning support to learners. On whether the respondents thought the midwife's competence contributed to how he/she worked with student midwives, $98.4 \%$ of the respondents said yes. Most of the respondents (56.5\%) stated that clinical supervision should be done by a "Competent" reflective midwife. On whom the respondents considered to be a competent midwife, most respondents (86.3\%) said it is a Skilful and critical decision maker. The finding was similar with the FGD as participants said the one who was a competent midwife was able to practice and make decisions that are critical. This attribute was considered more valuable for a supervisor to be able to transfer skills and knowledge effectively. Most nurses and midwives usually learn by observing a skillful practitioner thus emphasizing the need to help students become competent. "The clients also feel safe when being attended to by a skillful midwife". This shows that both the tutors and clinical supervisors have a vital role to help nurses and midwives become competent and critical decision makers since the profession deals with lives.

With regards to what contributes to acquisition of competence $51.6 \%$ of the respondents mentioned "working" according to guidelines of the profession. On what they thought could help student midwives acquire competences, $69.4 \%$ of 
the respondents said it is experienced staff, followed by $24.2 \%$ who said it is staffing levels. Concerning how they ensured the progress of students during clinical practice, $51.6 \%$ of the respondents said by meeting with clinical staff, $32.3 \%$ said by weekly reports, $24.2 \%$ said by monthly reports, and $16.1 \%$ said by "Other means". These findings reveal that most supervisors use meetings with clinical staff as a method of ensuring students' progress. The monthly and weekly reports are not usually used. Records that are documented as reports have a powerful and lasting benefits in monitoring students' progress as these may act as reference points to help students. If a student requires help the reports may be useful to notice areas of weaknesses since these as kept as records for the wards, school and students can also reflect on the reports to see areas they need to improve in. The fact that fewer respondents reported to be using reports also demonstrates the poor documentation in among nurses and midwives. This is like not monitoring a child's growth and development; a vital aspect to assess individual's physical and mental development. The results may prove disastrous as important indicators to progress would have been missed early and delayed identification becomes very difficult and too costly if not impossible to treat.

The present study revealed that methods used for evaluating midwifery Students' progress during clinical placement were continuous evaluation (72.6\%), demonstration (62.9\%), workbooks (49.2\%) semester evaluation (21\%) and others $5.6 \%$. This finding is attributed to different levels of professional qualification and knowledge on supervision. The study findings under demographic characteristics revealed that more than $89 \%$ of respondents said they had not been trained in supervision. This is supported by FGD findings which revealed that most undergraduate nurses and midwives are not trained in clinical supervision contributing to lack of knowledge on use of different evaluation methods. The three dominant methods (Continuous evaluation, demonstration and workbooks) are used as compulsory duty expected of staff working with students.

Most respondents (41.9\%) said that feedback was given on "Other times", $33.1 \%$ said they gave feedback "when students requested for it", $27.4 \%$ said they gave feedback at the end of the course and $22.6 \%$ said they gave feedback at the end of the semester. The other time refers to times other than the ones that were outlined; these include end of clinical allocation, annual feedbacks after end of year examinations and following assessments. It worth noting that a proportionally large number of respondents (33.1\%) would give feedback when students requested for it. This may entail students not receiving feedbacks if staff is not prompted by students. The overall supervisors' knowledge levels on clinical supervision show that the majority of the respondents $48.4 \%$ of the respondents had moderate knowledge. The gap in knowledge by the clinical supervisors could be attributed to lack of training in clinical supervision. This finding is supported by a study Mwale and Kalawa which was conducted in Malawi who reported that knowledge gap between nurses and tutors hindered clinical skill 
acquisition by students. Another study revealed that the theory-practice gap is felt most acutely by student nurses. They find themselves torn between the demands of their tutor and practicing nurses in real clinical situations [10] [11] [17]. A number of Nursing and Midwifery educational theorists recommend use of different strategies to help students acquire knowledge. They were faced with different real clinical situations and are unable to generalise from what they learnt in theory. This shows how vital knowledge is if consistency has to be maintained in what is taught to students. Tutors may teach theory most of the time but on the clinical area the staff may not be acquainted with new concepts since most people depend on experiential learning without referring to literature to keep up to date with evidence based practice.

\section{Attitude of Supervisors towards Clinical Supervision of Students}

The attitude of supervisors was measured using a likert scale with scores ranging from 1 to 5 . An effective supervisor is expected to be friendly, approachable, and aware of the standard of work expected from a student. On whether student midwives clinical supervision of midwives was necessary, all the respondents agreed with the statement. Furthermore, all the respondents (100\%) agreed with a statement that student midwives should be supervised during clinical experiences. This finding suggests that all the clinical supervisors' attitudes towards clinical supervision were positive. The findings of this study are consistent with the literature available on the attitude of supervisors as positive attitudes have been reported previously [11].

The FGD revealed that most nurses and midwives believe the task of supervision is for the clinical instructors and academic staff. The FDG also revealed that the attitude of staff towards clinical supervision is mainly negative as most consider this as added responsibility to their usual tasks. Participants stated that time was limited and they had increased workload to supervise students. Other staff were said to have lack of interest in supervising students and that the task was challenging. The positive finding from FGD participants was that they would want to have a midwife who has good attitudes, competent, skillful and knowledgeable.

\section{Competence of Supervisors}

The respondents were requested to state competences a supervisor should possess. Most respondents stated that a supervisor should know the examination of pregnant woman (86.3\%) this was followed by management of labour and newborn examination (83.9\%), examination of the postnatal woman $82.2 \%$, while $54 \%$ stated other procedures. These findings reveal that nurses and midwives have competence in key midwifery procedures. The FDG participants also highlighted that a good supervisor should be competent to help mold the students and encourage them to practice to acquire the competences. ICM and GNC also 
outlines the importance of student midwives and practicing nurse midwives to be competent before being licensed to practice [3] [16] [17]. On how to help students make critical decisions when practicing, $65.3 \%$ of the respondents mentioned that students should be assigned different tasks. These findings suggest that most staff expect students to practice more to be critical thinkers. The participants in the FDG on the other hand complained that doing different tasks makes students fail to meet their objectives during practice. Respondents suggested the availing of objectives to both students and staff so that their work is guided. GNC [3] standards and the midwifery curriculum stipulate that students are to be given objectives as they go for clinical practice. Nursing education books also stipulated that students require objectives for them and teachers including supervisors to know what is expected of them during clinical practice [1] [7] [9].

In addition, students who participated in the focus group discussion also confirmed the fact that they were send to different tasks as indicated by this response from one participant "Yes the staff give us a lot of tasks in the ward and by the time we knock off we could have not done the procedures related to our objectives for the allocation". Sending students to do different tasks put them at a disadvantage because they did not have time to practice and acquire the required competencies within the stipulated time. The ICM standards for 2011 states that competence is the combination of knowledge, psychomotor, communication and decision-making skills that enable an individual to perform a specific task to a defined level of proficiency; in this case a student midwife may be prepared to skillfully carry out midwifery duties. Proficiency takes time for one to attain and requires supervision by a competent proficient practitioner for one to have it.

With regards to the overall competences of the clinical supervisors, the current study revealed that most respondents (73\%) exhibited competence in clinical supervision of student midwives. The clinical supervisors were mainly able to handle key midwifery procedures competently (Examination of pregnant women, manage a woman in labour, care for the postnatal mother and newborn). The ICM and GNC standards clearly define what a midwife should be able to done before being licensed to practice. Cases of malpractice are dealt with according to regulatory provisions, this minimizes the use of incompetent staff by health institutions.

\section{Learning Environment of Students}

The learning environment included staffing levels to aid with supervision of students, materials and supplies and students learning objectives. As reported by the respondents, the staffing levels in the clinical areas were inadequate (69.4\%). This findings reflects the current situation on the ground. Zambia is experiencing a critical shortage of human resource for health as a result of brain drain and employment free due to the economic recession. The participants in the FDG 
stated that there were few staff working with them in clinical area due to inadequate staffing. In addition similar findings were recorded from FGD as remarked by this participant "At present there is a critical shortage of clinical Instructors; at the time of data collection the school of midwifery had only two clinical instructors and one had even gone to school". This finding is in line with a study which reported similar findings in Malawi where $70 \%$ of respondents mentioned inadequate staffing as a factor influencing students learning in the clinical area and reaffirmed in another study [11] [19].

In this study, most respondents $(62.9 \%)$ stated that the materials supplies and equipment to enable students learn were lacking in the clinical areas. Lack of material supplies and equipment could be attributed to the economic status of the country and population of students in the clinical areas. This finding was reaffirmed by one participant in group two FGD who said "there is need to have adequate resources especially training materials and equipment to enable students practice adequately and put in practice theoretical concepts." Analysis of data revealed that students learning objectives were availed to the clinical supervisors when students went for clinical allocation (80.6). This could be attributed to the fact the group Tutors are tasked with the responsibility to ensure that clinical objectives are avail to the clinical areas during each allocation.

The overall assessment of the learning environment by the respondents revealed that most respondents $(61 \%)$ described the learning environment as poor. This is attributed to shortage of staff, equipment and material resources. Some respondents complained of having higher numbers of students in clinical areas which contribute to difficulty in supervising them, thus some students may even miss work without being noticed. When students are too many in the clinical area than the patient population others end up not practicing at all unless those who are assertive and active.

\section{Conclusions and Recommendations}

The findings showed that a high percentage of the clinical supervisors had not been trained in clinical supervision and most respondents had moderate knowledge on clinical supervision of students. The attitude of supervisors towards supervision was positive. A large percentage of respondents were competent in clinical supervision. However the learning environment considered to be poor. The study revealed a significant association between clinical supervision and the respondents' knowledge on clinical supervision. There is need therefore to train clinical supervisors and improve the students learning environment in order to enhance teaching and learning.

The study recommends that Lusaka schools of Nursing, Midwifery and Theater together with the GNC should train more Clinical Instructors. The wards should have adequate numbers of Nurses and Midwives to adequately carry out their assigned tasks which include working with student midwives. This may help guide students to focus on critical areas of their training than doing routine 
work since training period is specified to avoid losing time on what is already known. Staffs working with students need to undergo training in clinical supervision as this may benefit even newly qualified staffs who may also need to be supervised as they graduate from being students to professional nurses and midwives. Lusaka Schools of Nursing Midwifery and Theatre should ensure that enough material resource especially equipment and training materials to use when imparting knowledge to students in various clinical sites.

\section{Strength and Limitations of the Study}

The study involved staffs who were familiar with work of supervision of students as they worked with student midwives. Student midwives who were involved in focus group discussion were Registered Nurses already some of whom may have even participated in the work of supervision of student midwives from their facilities and as they were training.

The primary limitation of this study was inadequate published literature on the study topic locally. The study was conducted in Lusaka province, thus the findings may not be generalized to the entire country. The use of self-report affected the length of data collection as staffs were usually busy. The response rate to the questionnaires took a longer time than planned increasing the costs planned to collect data.

\section{Acknowledgements}

The authors acknowledge the Ministry of Health for partly funding the study and participants for participating in the study.

\section{Copyright}

All rights reserved. No part of this dissertation may be reproduced or by any means without prior permission in writing from the author or the University of Zambia.

\section{References}

[1] O'Connor, A.B. (2014) Clinical Instruction and Evaluation-A Teaching Resource. 3rd Edition. Jones and Bartlett Publishers, Canada.

[2] Franklin, N. (2013) Clinical Supervision in Undergraduate Nursing Students: A Review of the Literature. E-Journal of Business Education \& Scholarship of Teaching, 7, 34-42.

[3] General Nursing Council of Zambia (2010) Registered Midwife Curriculum. GNC, Lusaka.

[4] Mellish, M.J., Brink, H. and Paton, F. (2000) Teaching and Learning the Practice of Nursing.4th Edition, Heinemann, Johannesburg.

[5] Ayo, E.N.S. (2006) Factors Influencing Clinical Teaching of Midwifery Students in a Selected Clinical Setting in Tanzania. University of South Africa, Pretoria.

[6] Government of Zambia (1997) Act No. 31 of 1997-Nurses and Midwives. Government Printers, Lusaka. 
[7] Quinn, F. M., and Hughes, S.J. (2013) The Principles and Practice of Nursing Education. 5th Edition, Cengage Learning, London.

[8] Waner, T., Johonson, U.B., Papastavrou, E., Tichelaar, E., Tamietto, M., den Bossche, K.V. and Saankoski, M. (2010) An Exploration of the Clinical Learning Experiences of Nursing Students in Nine European Countries. Nurse Education Today, 30, 809-815. https://doi.org/10.1016/j.nedt.2010.03.003

[9] Hinchliff, S.M. (1979) Teaching Clinical Nursing. Churchill Livingstone, London.

[10] Tebes, J.K., Matlin, S.L., Migdole, S.J, Farkas, S.M., Money, S., Shulman, R.W. and Hoge, M.A. (2011) Providing Competency Training to Clinical Supervisors through an Interactional Supervision Approach. Research on Social Work Practice, 21, 190-191. https://doi.org/10.1177/1049731510385827

[11] Mwale, G.O. and Kalawa, R. (2016) Factors Affecting Acquisition of Psychomotor Clinical Skills by Student Nurses and Midwives in CHAM Nursing Colleges in Malawi: A Qualitative Exploratory Study. BMC Nursing BMC Series-Open, Inclusive and Trusted, 15, 30.

[12] Polit, D.F., and Beck, C.T. (2012) Nursing Research: Generating and Assessing Evidence for Nursing Practice. 9th Edition, Lippincott Williams \& Wilkins, Philadelphia.

[13] Grove, S.K., Burns, N. and Gray, J.R. (2013) The Practice of Nursing Research-Appraisal, Synthesis, and Generation of Evidence. 7th Edition, Elsevier Saunders, St. Louis.

[14] Setumo, L.J. (2013) Midwifery Students' Experiences of Clinical Teaching at Sovenga Campus (Limpopo College of Nursing), Limpopo Province. University of South Africa, Pretoria.

[15] Lyth, G.G.M.M. (2000) Clinical Supervision: A Concept Analysis. Journal of Advanced Nursing, 31, 722 \pm 729 . https://doi.org/10.1046/j.1365-2648.2000.01329.x

[16] Sharif, F. and Masoumi, S. (2005) A Qualitative Study of Nursing Student Experiences of Clinical Practice. BMC Nursing, 4, 6. https://doi.org/10.1186/1472-6955-4-6

[17] International Confederation of Midwives (2012) Review of Each ICM Competence. http://internationalmidwives.org/

[18] O’Brien, A., et al. (2014) Evaluating the Preceptor Role for Pre-Registration Nursing and Midwifery Student Clinical Education. Nurse Education Today, 34, 19-24. https://doi.org/10.1016/j.nedt.2013.03.015

[19] Heidari, M.R. and Norouzadeh, R. (2015) Nursing Students' Perspectives on Clinical Education. PubMed. Nursing and Midwifery School, Shahed University, Tehran. 